\title{
LIBERDADE INDIVIDUAL, DIREITO FUNDAMENTAL AO ACESSO À DEFESA - EVOLUÇÃO DA LEGISLAÇÃO PÁTRIA SOBRE ARMAS
}

\section{INDIVIDUAL FREEDOM, FUNDAMENTAL RIGHT TO ACCESS TO DEFENSE - EVOLUTION OF THE NATIONAL LEGISLATION ON WEAPONS}

Jaelson da Silva Ramos

Gleiton Gonçalves de Souza²

Bacharelando em Direito pela Universidade Paranaense - UNIPAR.

E-mail: jaelsonjp@hotmail.com

${ }^{2}$ Bacharel em Direito pela Universidade Paranaense - UNIPAR. Mestre em Direito pela Universidade Estaudal de Maringá - UEM. Tem experiência na área de Direito, com ênfase em Teoria do Direito, atuando nos seguintes temas: responsabilidade civil, responsabilidade ambiental, danos materiais e morais no contrato de trabalho, cheques e títulos de crédito. Atualmente é advogado e professor da UNIPAR.

E-mail: gleiton-adv@uol.com.br
Recebido em Julho de 2021

Aceito em Agosto de 2021
RAMOS, J. da S.; SOUZA, G. G. de. Liberdade individual, direito fundamental ao acesso à defesa - evolução da legislação pátria sobre armas. Akrópolis, Umuarama, v. 29, n. 2, p. 223-236, jul./ dez. 2021.

\section{DOI: $10.25110 / a k r o p o l i s . v 29 i 2.8568$}

Resumo: O presente artigo, fundamentado em uma pesquisa bibliográfica e em dispositivos legais, tem por finalidade, analisar as possibilidades de posse e porte de arma de fogo, como um direito fundamental à própria defesa e a liberdade individual, aplicando uma visão crítica sobre os atos de restrições em relação à defesa própria (de si) e alheia (de outrem) objetivando dar maior efetividade aos direitos individuais fundamentais ligados à própria existência. A Constituição Federal garante para cada cidadão o direito à liberdade, e é através dela que haverá a possibilidade plena de proteção da vida, visto que a eficácia do Estado na proteção desses direitos é relativamente baixa. A pesquisa demonstra que o melhor caminho é a criteriosa liberação do acesso aos meios protetivos individuais, inclusive em relação às armas de fogo. Por criteriosa, não se pode entender a proibição disfarçada que atualmente se verifica no aparato federal de (des)aprovação dos pedidos de registro de arma de fogo. O estudo demonstra que a vedação ao acesso, em que se transformou ilegitimamente o conjunto de restrições impostas pelo aparato de fiscalização, fere o direito à liberdade do indivíduo, bem como, ao direito fundamental a defesa própria e dos seus.

PalaVras-chave: Liberdade individual; Direito fundamental; Acesso à defesa; Armas de fogo.

Abstract: This study, based on bibliographic research and on legal provisions, aims at analyzing the possibilities of ownership and possession of firearms as a fundamental right to self-defense and individual freedom, applying a critical view on acts of restrictions in relation to self-defense (to oneself) and to someone else (of others) with the objective of giving greater effectiveness to the fundamental individual rights connected to everyone's own existence. The Federal Constitution guarantees the right to freedom for every citizen, and it should provide the full possibility of protection of life, inasmuch as the State's effectiveness in protecting these rights is relatively low. This study demonstrates that the best way is to have a balanced liberation of access to individual protective means, also in relation to firearms. Balanced does not mean the disguised prohibition that currently exists in the federal apparatus for (dis)approval of requests for registration of firearms. This study also demonstrates that the prohibition of access, 
which illegitimately transformed the set of restrictions imposed by the inspection apparatus, violates the individual's right to freedom, as well as the fundamental right to self-defense and the defense of those under their care.

KeYwORDS: Individual freedom; Fundamental right; Access to defense; Firearm.

\section{INTRODUÇÃO}

O tema sobre o porte e posse de armas de fogo, regulamentadas pelo Estatuto do Desarmamento, em tempos e tempos volta a fazer parte dos debates no cenário político nacional. É notório que ganhou maior força no pleito eleitoral de 2018, em que Jair Messias Bolsonaro, atual presidente do país, acrescentou em seu plano de governo a proposta de flexibilização do armamento civil.

Esse debate, em torno das politicas públicas adotadas pelo governo federal que restringem o porte de armas de fogo, não é uma novidade no país, visto que as normas de regulamentação presentes no Brasil parte desde o início do império e foi se moldando até chegarmos às normas atuais.

O trabalho tem como base, além das diversas obras de especialistas no assunto, a Constituição Federal, que contempla a sociedade em seu todo, e o cidadão em sua individualidade.

Buscamos demostrar por meio de princípios constitucionais que o acesso aos meios protetivos é um direito fundamental no tocante a liberdade individual e que o Estado é incumbido de garantir que todo cidadão seja respeitado em sua plenitude, devendo não restringir, mas ampliar, com a regulamentação necessária, o direito individual em sua liberdade de ter a posse e o porte de arma de fogo.

Em contrapartida, no debate sobre a liberdade individual ao acesso à defesa, o que muitas das vezes se pauta, não são os números, pesquisas ou estudos científicos do tema, mas o viés ideológico é que se faz presente, prejudicando o principal interessado que é o povo.

Outro ponto importante que abordamos são os efeitos práticos causados pelo Estatuto do Desarmamento na sociedade, vez que ao entrar em vigor estabeleceu normas que alterou o regulamento de armas de fogo, proibindo o seu porte pelo cidadão comum, salvo em casos extremamente especiais.
A natureza fundamental do direito à vida e à integridade física requer os meios necessários para sua proteção, instrumentos capazes de repelir um possível dano, a necessidade desses instrumentos se dá pela insuficiência dos meios físicos de cada cidadão (habilidade ou força insuficiente para a autodefesa).

O direito individual ao acesso à defesa de si próprio deve estar alicerçado na existência de meios lícitos, regulados pelo Estado de forma não restritiva, como ocorre no atual Estatuto.

\section{EVOLUÇÃO HISTÓRICA E CONCEITOS LEGAIS}

\subsection{Evolução histórica do trato legal das armas}

Quando abordamos a capacidade racional e, consequentemente, a capacidade intelectual do ser humano, notamos que sua evolução no decorrer dos séculos é algo grandioso. Conceitos e mais conceitos foram criados para o aperfeiçoamento harmônico do homem no seio da sociedade.

Surgiram, até chegarmos aos dias atuais, desde regras de etiquetas, a mais suprema lei de países democráticos, como as Constituições, com outros países indo além, aderindo aos Tratados que inserem os países signatários numa norma sem barreiras territoriais.

Nota-se, contudo, que entre séculos e séculos, geração em geração, o homem sempre buscou a sua proteção e de sua família e de tudo aquilo que lhe pertence.

Essa busca, por meios de proteção, foi se aperfeiçoando conforme a sua evolução na convivência social, ao ponto de chegar a maior quantidade bélica nunca antes existente na história.

Assim, desde os primeiros registros
históricos, as armas estão presentes no
mundo, seja para a proteção ou uso como
mecanismo para conseguir alimentos (a
exemplo da caça e pesca). O homem fazia
uso de ferramentas como pedras, madeira
e outros tipos de objetos para cortar a pele
de animais resultantes da própria caça,
bem como para a proteção de si mesmo, da
sua propriedade e de sua família.

A necessidade de se ter proteção sempre foi uma busca do ser humano e, aos poucos, os meios encontrados foram tornando-se mais eficazes, 
e o que no começo eram apenas pedras e paus, evoluiu ao longo do tempo, como relata Teixeira (2018, p. 13):

Assim, desde seu surgimento na face da Terra até os dias atuais, o homem se utiliza de algum meio para efetuar sua autodefesa. Apenas o que mudou foram as armas ou os meios utilizados, que acompanharam 0 , a descoberta de novos materiais e as novas tecnologias que surgiram ao longo da própria evolução humana.

Percebe-se, dessa forma que, com o passar do tempo, descobriram-se outros materiais mais eficazes para a sua proteção, dentre eles o metal. As armas que até então eram feitas de pedras e madeiras, deram lugar a armas feitas de aço, como lâminas, denominadas atualmente como armas brancas.

Embora não se saiba ao certo o período que foi descoberta, a pólvora resultou no maior avanço histórico na evolução das armas. Alguns autores citam como descoberta na Idade Média, outros atribuem ao século I, ainda há outros que afirmam que a sua descoberta é anterior a Cristo.

A simples menção histórica faz-nos perceber que, desde o princípio, proteger a si mesmo e aos seus e, principalmente o que se ama, é uma busca intrínseca do ser humano. Ao criar armas, o homem buscou suprir as suas limitações físicas, seja na caça ou na proteção contra os mais fortes.

\subsection{Conceitos legais}

Mesmo que a nossa imaginação, por muitas vezes, possa nos levar a crer que as questões em torno das armas de fogo é simplesmente andar por aí com uma arma na cintura, existe em nosso ordenamento jurídico uma gama de denominações que diferenciam uma das outras no seu significado e, principalmente, na ação prática de uso.

Tais denominações, como porte, posse e arma de fogo, têm não apenas significados, mas conceitos diferentes, os quais, no momento em que os compreendemos, tornam-se mais objetivos a identificação legal e, o mais importante, estabelece uma ideia mais clara sobre as armas para aqueles que as desejam possuir.

No dicionário Aurélio, Ferreira (2010, p. 62) traz uma definição, comumente usada sobre o que é arma:
Arma. [Lat. arma.] S.F 1. Instrumento de ataque ou de defesa. 2. Qualquer objeto que sirva para tais fins. 3.V. arma de fogo. 4. Cada uma das subdivisões básicas da tropa do exército: infantaria, cavalaria, artilharia, engenharia, comunicações. 5. Recurso, expediente. Arma branca. Qualquer arma constituída de lâmina e cabo. Arma de fogo. A que lança projetis por meio da detonação de uma carga explosiva, com fogo ou de modo mecânico.

Em regra geral arma significa um instrumento de ataque ou de defesa, como bem menciona Ferreira, podendo alcançar as armas brancas e as armas de fogo.

Contudo, como podemos observar que as armas não estão especificadas apenas em arma branca ou de fogo, o critério a ser usado para a identificação de uma arma é o uso e não o objeto (em regra geral) ${ }^{3}$. Nesse sentido, existe uma infinidade de armas, a quantidade de objetos para tal uso é grande, exemplos não faltam, vejamos:

"Advogado mata cliente com caneta e martelo após discussão"4.

"Bombas de Boston seriam feitas de panela de pressão, pregos e metal" 5 .

"Ataque com caminhão deixa dezenas de mortos em Nice, no sul da França" ${ }^{\text {. }}$

"Homem mata amante da companheira com golpes de violão na cabeça, diz polícia"7.

"Homem mata opositor político em bar, usando um garfo de churrasco, que buscou em casa"8.

Logo, objetos de uso cotidiano podem se transformar em armas letais, inclusive um violão.

$\mathrm{Na}$ legislação sobre as armas, o decreto

\footnotetext{
${ }^{3}$ Trata-se de arma num todo e não arma de fogo exclusivamente.

4 Disponível em: https://www.metropoles.com/brasil/policia-br/ advogado-mata-cliente-com-caneta-e-martelo-apos-discussao?amp. Acesso em: 23 set. 2020 .

5 Disponível em: http://g1.globo.com/mundo/noticia/2013/04/bombasde-boston-seriam-feitas-de-panela-de-pressao-pregos-e-metal.html. Acesso em: 23 set. 2020.

6 Disponível em: http://g1.globo.com/mundo/noticia/2016/07/veiculoatinge-multidao-em-queima-de-fogos-do-14-de-julho-em-nice.html.
} Acesso em: 23 set. 2020.

7 Disponível em: https://g1.globo.com/sp/sorocaba-jundiai/noticia/ homem-mata-amante-de-companheira-com-golpes-de-violao-nacabeca.ghtml. Acesso em: 23 set. 2020.

Disponivel em: https://www.correiobraziliense.com.br/ brasil/2020/10/4883547-homem-mata-opositor-politico-em-barusando-um-garfo-de-churrasco-que-buscou-em-casa.html. Acesso em: 23 set. 2020. 
$\mathrm{n}^{\circ} 3.665$, de 20 de novembro de 2000, que regulamentava a fiscalização de produtos controlados, trazia definições não muito dissonantes do dicionário Aurélio sobre armas em seu artigo terceiro, como podemos ver a partir do inciso IX:

Art. 3o Para os efeitos deste Regulamento e sua adequada aplicação, são adotadas as seguintes definições:

IX - arma: artefato que tem por objetivo causar dano, permanente ou não, a seres vivos e coisas;

XI - arma branca: artefato cortante ou perfurante, normalmente constituído por peça em lâmina ou oblonga;

XIII - arma de fogo: arma que arremessa projéteis empregando a força expansiva dos gases gerados pela combustão de um propelente confinado em uma câmara que, normalmente, está solidária a um cano que tem a função de propiciar continuidade à combustão do propelente, além de direção e estabilidade ao projétil.

Esse decreto foi revogado, passando a vigorar o decreto 10.030 de 2019, que no anexo III, agora de controle do Exercito, define as armas de fogo como:

[...] que arremessa projéteis empregando a força expansiva dos gases, gerados pela combustão de um propelente confinado em uma câmara, normalmente solidária a um cano, que tem a função de dar continuidade à combustão do propelente, além de direção e estabilidade ao projétil.

Reforçando o entendimento, quando tratamos única e, exclusivamente de arma, no sentido geral, a finalidade do agente é o que predomina, a sua intenção sobre como usar o objeto é que irá configurar a arma. Com isso, o critério objetivo, que é empregado na distinção de armas de fogo e armas brancas, dá lugar ao critério subjetivo, em que é a vontade, a finalidade do uso de um objeto, até então inofensivo, que poderá se tornar uma arma com a capacidade de matar.

No tocante à arma de fogo, a intenção de quem a usa deve ser levada em consideração e não apenas a arma em si, vez que ela é um objeto e que vontade nenhuma há de fazer algo, se não a de quem a possui.

Abordando as características da arma de fogo, que é tema principal do nosso trabalho, há de se distinguir os conceitos de posse e porte de arma de fogo, sendo que o primeiro é permitido no Brasil, enquanto o segundo, afirma Quintela e Barbosa (2015, p. 134): "o artigo $6^{\circ}$ deixa claro que se 0 cidadão não trabalha nas Forças Armadas, nem na força policial, e nem nas empresas de segurança, ele não pode portar uma arma".

Pois bem, o porte de armas de fogo é proibido no Brasil desde 2003, e as profissões citadas na referência do parágrafo anterior são retiradas do estatuto do desarmamento (Lei $n^{\circ}$. 10.826 de 22 de dezembro de 2003) o qual estabeleceu quem pode ter o porte de armas de fogo em seu artigo $6^{\circ}$ :

Art. $6^{\circ}$ É proibido o porte de arma de fogo em todo o território nacional, salvo para os casos previstos em legislação própria e para:

I - os integrantes das Forças Armadas;

II - os integrantes de órgãos referidos nos incisos I, II, III, IV e V do caput do art. 144 da Constituição Federal e os da Força Nacional de Segurança Pública (FNSP);

III - os integrantes das guardas municipais das capitais dos Estados e dos Municípios com mais de 500.000 (quinhentos mil) habitantes, nas condições estabelecidas no regulamento desta Lei;

IV - os integrantes das guardas municipais dos Municípios com mais de 50.000 (cinquenta mil) e menos de 500.000 (quinhentos mil) habitantes, quando em serviço;

V - os agentes operacionais da Agência Brasileira de Inteligência e os agentes do Departamento de Segurança do Gabinete de Segurança Institucional da Presidência da República;

VI - os integrantes dos órgãos policiais referidos no art. 51, IV, e no art. 52, XIII, da Constituição Federal;

VII - os integrantes do quadro efetivo dos agentes e guardas prisionais, os integrantes das escoltas de presos e as guardas portuárias;

VIII - as empresas de segurança privada e de transporte de valores constituídas, nos termos desta Lei;

IX - para os integrantes das entidades de desporto legalmente constituídas, cujas atividades esportivas demandem o uso de armas de fogo, na forma do regulamento desta Lei, observando-se, no que couber, a 
legislação ambiental.

X - integrantes das Carreiras de Auditoria da Receita Federal do Brasil e de Auditoria-Fiscal do Trabalho, cargos de AuditorFiscal e Analista Tributário.

$\mathrm{XI}$ - os tribunais do Poder Judiciário descritos no art. 92 da Constituição Federal e os Ministérios Públicos da União e dos Estados, para uso exclusivo de servidores de seus quadros pessoais que efetivamente estejam no exercício de funções de segurança, na forma de regulamento a ser emitido pelo Conselho Nacional de Justiça CNJ e pelo Conselho Nacional do Ministério Público - CNMP

Há duas exceções para se ter o porte de arma de fogo, além de Forças Armadas, força policial e empresas de segurança, seriam os praticantes de tiro esportivo e os auditores federais. Mesmo assim, parece-nos um pouco precipitado afirmar que os praticantes de tiro esportivo têm esse direito, visto que este possui a denominada Guia de Tráfego e não o porte em si, e que no deslocamento até o estande de tiro, conforme menciona Quintela e Barbosa (2015), "só pode levar sua arma desmuniciada".

Seria forçoso, com tantas restrições assim, afirmar que se trata de um direito.

O texto legal é claro ao afirmar que "é proibido o porte de arma de fogo em todo território nacional", e mesmo completando que é permitido o porte nos casos que a própria lei determine e que em nenhum caso contempla o cidadão comum, fica evidente a vedação do porte de arma de fogo, seja em qualquer circunstância.

Já no tocante à posse de arma de fogo, o texto do Decreto 9.845/2019, que também regulamentou o estatuto do desarmamento, traz a possibilidade da pessoa civil ter a posse de arma de fogo, como podemos ver no art. $4^{\circ}$ :

Art. $4^{\circ} \mathrm{O}$ Certificado de Registro de Arma de Fogo, expedido pela Polícia Federal, precedido de cadastro no Sinarm, tem validade no território nacional e autoriza o proprietário a manter a arma de fogo exclusivamente no interior de sua residência ou nas dependências desta, ou, ainda, de seu local de trabalho, desde que seja ele o titular ou o responsável legal pelo estabelecimento ou pela empresa.
Assim, ter a posse da arma de fogo é possível e essa posse significa poder mantê-la sob sua guarda na residência ou no trabalho, desde que seja proprietário do estabelecimento ou o responsável legal por ele.

Ao cidadão que deseja ter a posse de uma arma de fogo, há a necessidade de ter todas as condições impostas pela lei e mesmo cumprindo com todos os requisitos objetivos, a posse da arma de fogo estará nas mãos da autoridade competente, pelo critério subjetivo da declaração de efetiva necessidade, visto que a lei não diz o que é a efetiva necessidade. nosso).

Eis a afirmativa, conforme texto legal (grifo

Art. 4o Para adquirir arma de fogo de uso permitido o interessado deverá, além de declarar a efetiva necessidade, atender aos seguintes requisitos:

I - comprovação de idoneidade, com a apresentação de certidões negativas de antecedentes criminais fornecidas pela Justiça Federal, Estadual, Militar e Eleitoral e de não estar respondendo a inquérito policial ou a processo criminal, que poderão ser fornecidas por meios eletrônicos;

II - apresentação de documento comprobatório de ocupação lícita e de residência certa;

III - comprovação de capacidade técnica e de aptidão psicológica para o manuseio de arma de fogo, atestadas na forma disposta no regulamento desta Lei.

Não restam dúvidas que o que existe na legislação brasileira é uma propagação ao desarmamento, com leis cada vez mais restritivas, ao ponto de apenas uma minoria com condições financeiras ter a possibilidade de adquirir uma arma de fogo, e mesmo assim, essa minoria estará sujeita ao critério subjetivo da efetiva necessidade, tornando dificultosa a posse até para essa minoria, levando parecer ser, um "privilégio ao cidadão, e não um direito" (QUINTELA; BARBOSA, 2015).

\subsection{Estatuto do desarmamento - premissas, verdade e falácias}

O processo legislativo brasileiro, mesmo antes da República, já buscava regulamentar a relação entre cidadão e arma de fogo, e essa regulamentação foi se tornando, com o passar do 
tempo, cada vez mais restritiva, ao ponto de que, nos dias atuais, nossa legislação, comparada na esfera internacional, encontra-se entre as mais restritivas que existem, longe de ser uma regulamentação liberal, assim não há como afirmar que nossa legislação garante como direito fundamental o acesso à defesa.

Ao analisar o Estatuto do Desarmamento, em sua estrutura e principalmente na ideia de uma solução para os homicídios, um problema que se alastra há séculos no Brasil, nota-se que o Estatuto não cumpriu com suas metas, pelo contrário, desde sua vigência o país registrou recordes de homicídios ano após ano, o que agrava ainda mais a situação, uma vez que o Estatuto não conseguiu manter o índice de homicídios, evitando seu crescimento, muito menos diminuir a quantidade de homicídios anualmente da época, propaganda central na campanha para a aceitação social do estatuto em vigor.

No princípio, o que prevaleceu no Brasil eram as normas do Reino de Portugal, dessa forma, "nas fases primitivas da colonização do Brasil não havia legislação própria no país, vigorando, portanto, as Ordenações Afonsinas (1446-1521), Ordenações Manuelinas (1521-1603) e Ordenações Filipinas (1603-1867)"9.

Essas normas prevaleceram até 1830, momento em que foi promulgado o Código Criminal do Império do Brasil, que estabeleceu, entre outros crimes, o crime de uso de armas proibidas.

O Código Criminal do Império do Brasil, formulado para substituir o até então livro $V$ das ordenações Filipinas, é a primeira legislação que trata objetivamente da arma de fogo, como se pode ver no capítulo $\mathrm{V}$, que tratava sobre o uso de armas de defesas:

Art. 297. Usar de armas offensivas, que forem prohibidas.

Penas - de prisão por quinze a sessenta dias, e de multa correspondente á metade do tempo, atém da perda das armas.

Art. 298. Não incorrerão nas penas do artigo antecedente:

$1^{\circ}$. Os Officiaes de Justiça, andando em diligencia.

$2^{\circ}$. Os Militares da primeira e segunda linha, e ordenanças, andando em diligencia, ou em

\footnotetext{
Disponível em: https://www.portaldotiro.com/artigos-tecnicos/ legislacao-de-armas/534-leis-de-armas-de-fogo-conheca-o-historicoe-o-que-permanece-vigente. Acesso em: 10 set. 2020.
}

exercicio na fórma de seus regulamentos.

$3^{\circ}$. Os que obtiverem licença dos Juizes de Paz.

Art. 299. As Camaras Municipaes declararão em editaes, quaes sejam as armas offensivas, cujo uso poderão permittir os Juizes de Paz; os casos, em que as poderão permittir; e bem assim quaes as armas offensivas, que será licito trazer, e usar sem licença aos occupados em trabalhos, para que ellas forem necessarias.

O texto legal acima citado decorre do original, o qual traz consigo as normas linguísticas da época, mas fica claro que a pena por porte ilegal de arma, ou melhor, porte de arma proibida, era no máximo de sessenta dias de prisão, multa e a perda da arma, a partir desse período as novas normas que foram promulgadas trouxeram a regulamentação no tocante ao porte de armas.

O Código Penal de 1890 manteve as mesmas penas do código criminal do império, como podemos ver no que diz o capítulo V:

Art. 377. Usar de armas offensivas sem licença da autoridade policial:

Pena - de prisão cellular por 15 a 60 dias.

Paragrapho unico. São isentos de pena:

$1^{\circ}$. Os agentes da autoridade publica, em diligencia ou serviço;

$2^{\circ}$. Os officiaes e praças do Exercito, da Armada e da Guarda Nacional, na conformidade dos seus regulamentos.

As penas permaneceram iguais, tratando o porte ilegal de arma de fogo com pena de até sessenta dias de prisão, multa e a perda da arma.

Esse novo código ficou marcado pela nova introdução de prisão, a chamada prisão celular, que é a detenção em cela de estabelecimento prisional e que existe até os dias atuais.

Seguiu assim as novas legislações que entravam em vigor, punindo, mesmo que de forma tímida, o uso de arma ilegal ou proibida e permanecendo o reconhecimento do direito fundamental ao acesso a defesa. Prova disso é o Decreto $n^{\circ}$ 92.795, de 18 de junho de 1986. Decreto esse que concretizava em norma legal o que a sociedade já vivia desde o império com a preservação do direito a defesa.

Assim dispunha o caput: "Dispôs sobre 
o registro e a autorização federal para o porte de arma de fogo, de uso permitido, em todo o território nacional".

Importante ressaltar que, mesmo sendo uma norma com processo burocrático, não muito diferente da atualidade, e que continha o critério subjetivo, o qual tratava a autorização do porte como ato discricionário da Administração Federal, o porte não era proibido no Brasil.

Todavia, no ano seguinte as normas restritivas ganharam notoriedade no cenário nacional com a publicação da Portaria $n^{\circ} 222^{10}$, onde proibiu o direito do cidadão ao acesso à defesa, como afirma Neto: "Por ordem do Ministério da Justiça, foram cancelados todos os documentos federais de porte de arma de fogo, proibindo-se, inclusive, a emissão de novos, sob o argumento de colaborar para a diminuição da criminalidade no país [...]".

O argumento utilizado, na verdade uma propaganda sobre a proibição do porte de arma de fogo para o cidadão comum, é que haveria a diminuição da criminalidade, no entanto a meta não foi alcançada, claro desastre de uma politica de segurança pública sem comprovação científica.

Depois da Portaria $n^{\circ} 222$, as normas que vieram em seguida mantiveram e até mesmo aumentaram as restrições, dificultando cada vez mais a possibilidade do cidadão ter uma arma de fogo, mesmo que para a posse.

Essas políticas restritivas tiveram como referência as politicas de controle de arma de fogo da ONU, como o $9^{\circ}$ Congresso das Nações Unidas sobre Prevenção do Crime e Tratamento do Delinquente que ocorreu em 1995, que "abordou o tema de controle de armas de fogo, visando tutelar a segurança pública, em seu sentido amplo" (RODRIGUES NETO, 2020).

Outra grande influência para as normas restritivas no Brasil foi a Comissão de Prevenção do Crime e Justiça Penal, do Conselho Econômico e Social de Viena - Áustria em 1996, que "ficou consignado à recomendação de que os EstadosMembros deveriam fortalecer as suas legislações internas, tornando rígido o controle da aquisição, posse e porte de armas de fogo" (JESUS, 1998).

Essa influência da ONU resultou na instituição do SINARM (Sistema nacional de Armas) por meio da lei 9.437 de 1997, ganhado ainda mais

\footnotetext{
Disponível em: https://www.portaldotiro.com/artigos-tecnicos/ legislacao-de-armas/534-leis-de-armas-de-fogo-conheca-o-historicoe-o-que-permanece-vigente. Acesso em: 10 set. 2020.
}

força a campanha de desarmamento.

Entre outras razões, afirma Rodrigues Neto que dessa influência da ONU "há fortes indícios de que a adoção pela campanha de desarmamento no Brasil tenha relação com a intenção do governo brasileiro em ocupar uma cadeira permanente no Conselho de Segurança das Nações Unidas".

Bem, sem dúvida alguma a lei 10.926 conhecida como Estatuto do Desarmamento, foi o marco histórico na restrição do acesso a arma de fogo, tendo grande impacto na sociedade brasileira.

Rebelo (2019, p. 47) expõe que mesmo tendo um grande impacto na sociedade, o Estatuto do Desarmamento "ingressou no mundo jurídico sem a necessária discussão técnica sobre sua eficácia para a redução da violência, com debates tênues e restritos ao próprio Congresso Nacional".

O Estatuto do Desarmamento, além de revogar a lei 9.437 , torna como regra a vedação do porte de arma de fogo, com algumas exceções: Forças Armadas, força policial, empresas de segurança, praticantes de tiro esportivo e os auditores federais.

Em nenhum caso o cidadão comum é contemplado com o direito à defesa de si próprio, salvo com especial autorização.

Essa proibição só seria justificável se o Estado, com todo seu poderio, realizasse a efetiva proteção dos cidadãos, objetivo logicamente impossível, visto que materialmente o Estado é impedido de estar presente em todos os lugares ao mesmo tempo com a força policial.

Mesmo o Estado sendo o principal responsável pela garantia dos direitos fundamentais, sendo possuidor do dever e do compromisso de fazer cumprir todo o ordenamento na segurança física e patrimonial da sociedade, observa-se que sua ação na proteção desses direitos tem sido de grandes falhas no seu cumprimento, possibilitando, assim, criticar a postura proibitiva que se adotou em relação aos meios necessários para com os cidadãos quanto à respectiva proteção.

O fracasso das políticas proibitivas estabelecidas pelo Estado se dá, conforme números do próprio governo, com a não diminuição do índice de violência.

Os dados mostram que em 2004, ano que de fato teve a entrada em vigor do Estatuto do Desarmamento, tivemos 34.187 assassinatos por arma de fogo e 48.909 homicídios no total, enquanto em 2017, tivemos 47.510 assassinatos por arma de 
fogo e 65.602 homicídios no total ${ }^{11}$.

Em relação aos números não há o que duvidar, confirmando que a tese da redução da violência com o Estatuto do Desarmamento revelou-se numa propaganda enganosa, e que essa afirmação não estava alicerçada em nenhum estudo cientifico.

\subsection{Referendo de 2005 - Análise e resultado}

Com a aprovação do Estatuto do Desarmamento, no apagar das luzes, visto que se deu nos últimos dias de sessões legislativas (22 de dezembro de 2003), era de se esperar que a sociedade questionasse as medidas tomadas, ainda mais levando em consideração que a pauta estava revestida de viés ideológico e politização.

Em um país democrático as normas devem ser estabelecidas visando suprir as necessidades da população, e o processo realizado para isso é através da democracia. Em nosso sistema representativo o poder (Kratos) do povo (Demos) deve ser exercido por meio de representantes eleitos pelo povo e se o desejo do povo não é posto em realidade, o uso desse poder deveria passar a ser ilegítimo, pois estariam ferindo e desprezando o poder que em tese Ihes foram transferidos.

O artigo 14 da Constituição Federal trata dos direitos políticos do povo brasileiro, expressamente traz consigo a realidade democrática por meio do voto. Assim, o povo se torna parte principal e integrante do sistema democrático de direito, como afirma nossa Carta Magna, artigo 14 e incisos I e II que diz:

Art. 14. A soberania popular será exercida pelo sufrágio universal e pelo voto direto e secreto, com valor igual para todos, e, nos termos da lei, mediante:

I-plebiscito;

II-referendo;

Sobre o plebiscito e referendo, Lenza (2016) afirma que "a semelhança entre eles reside no fato de ambos serem formas de consulta ao povo para que delibere sobre matéria de acentuada relevância, de natureza constitucional, legislativa ou administrativa".

No Dicionário de Política de Bobbio, Matteucci e Pasquino, Gemma (p.1074)

${ }_{11}$ Dados do Instituto de Pesquisa Econômica Aplicada, disponível em: https://www.ipea.gov.br/atlasviolencia/ diferencia o referendo do plebiscito "por sua maior regularidade e, portanto, por ser objeto de disciplina constitucional".

Numa análise mais simplória, o plebiscito é a consulta popular antes da aprovação do projeto, já o referendo, é a consulta feita depois da aprovação do projeto.

Com a aprovação do estatuto do desarmamento, em 22 de dezembro de 2003, a compra, posse e registro de armas de fogo passaram a ter um controle mais rígido pela legislação, para Quintela e Barbosa (2015, p. 155) "a partir dessa data, o Brasil passou a contar com uma das legislações mais restritivas do mundo".

O que mais se esperava do estatuto do desarmamento depois de sua aprovação era o cumprimente da consulta popular por meio do referendo, expresso no artigo 35 e incisos I e II:

Art. 35. É proibida a comercialização de arma de fogo e munição em todo o território nacional, salvo para as entidades previstas no art. 60 desta Lei.

$\S 10$ Este dispositivo, para entrar em vigor, dependerá de aprovação mediante referendo popular, a ser realizado em outubro de 2005.

§ $20 \mathrm{Em}$ caso de aprovação do referendo popular, o disposto neste artigo entrará em vigor na data de publicação de seu resultado pelo Tribunal Superior Eleitoral.

Deu-se o referendo no dia 23 de outubro de $2005 \mathrm{com}$ a seguinte questão a ser respondida pelos eleitores: "O comércio de armas de fogo e munição deve ser proibido no Brasil?".

Conforme Relatório da Presidência do Senado Federal (2005, p. 1014), na época houve duas frentes parlamentares que buscavam fortificar suas campanhas, uma "PELO DIREITO DA LEGÍTIMA DEFESA"que defendia o NÃO, presidida pelo deputado federal Alberto Fraga e a outra "POR UM BRASIL SEM ARMAS" que defendia o SIM, presidida pelo senador Renan Calheiros.

O referendo buscava consolidar a vontade da população, se excluiria ou manteria o comércio de armas de fogo, tal pretensão foi plena e democraticamente rejeitada por meio de referendo, que depois de três meses de campanhas, debates e propagandas, o resultado foi divulgado no diário de justiça do Tribunal Superior Eleitoral, sendo o vencedor a opção NÃO com 59.109.265 votos, 
contra 33.333.045 da opção SIM.

A escolha da população foi clara ao se posicionar em NÃO a proibir o comércio de armas de fogo e munições, uma escolha democrática, respeitando a forma e o sistema realizado.

Essa foi uma manifestação clara do desejo popular, em que concerne na manutenção do comércio de armas de fogo e munição.

O objetivo inicial não era propor um referendo para que a população se manifestasse, colocando em ação seu poder soberano, mas de que a proibição fosse aprovada em texto legal pelos parlamentares sem consulta pública, impondo uma lei contrária a que era querida pela população.

A implementação do artigo 35, possibilitando a consulta popular, foi o resultado da movimentação feita por aqueles que se indignaram com a imposição de uma norma que não respeitava a vontade popular, que é soberana, e maculava a liberdade individual do cidadão, ao não preservar seu direito à defesa.

A manifestação da sociedade, para que não se proíba o comércio de arma de fogo e munições, é apenas uma demonstração do real seu desejo, que é o respeito e a proteção do Estado em relação às liberdades individuais no acesso à defesa.

Não podemos aceitar, nas afirmação de Carlos Drummond de Andrade (apud CAVALCAN$\mathrm{TI}$ ), que a democracia seja "a forma de governo em que o povo imagina estar no poder".

Ao votar pelo "não" a sociedade expressamente afirma que as armas, de forma legal, devem estar presentes em todo território nacional, possuindo assim, aqueles que as querem possuir, logo tendo a sua vontade respeitada.

Rebelo (2019, p. 201) afirma ainda que "o não dito nas urnas foi à lei vigente, mas o que vem sendo negado desde então é outra coisa, é a própria soberania popular, que assim parece repousar como adorno irrelevante em nossa Constituição $[\ldots] "$.

O porte e posse de armas de fogo devem ser regulados com mais liberdade e menos restrições, uma liberdade que, claro, deve ser feita com um processo criterioso, mas por criterioso, não se pode entender a proibição disfarçada, que atualmente se verifica no aparato federal de (des)aprovação dos pedidos de registro de arma de fogo.

\section{DIREITO FUNDAMENTAL AO ACESSO À DEFESA}

\subsection{Liberdade individual}

Em tempos de pandemia, em que muitos casos de violação a liberdade individual tem sido expostos no meio jornalístico, volta à tona o debate de até que ponto a liberdade do cidadão, em sua individualidade, pode sofrer restrições ou até mesmo violações por parte do Estado.

O direito fundamental da liberdade individual, assim como todos os direitos fundamentais, não são direitos absolutos, ressalvando o que cerne a realidade social, vez que o direito de um não pode ser danoso à sociedade.

Em contrapartida, a ideia de nenhum direito ser absoluto, não pode ser motivo para a ação de o Estado interferir sem uma real justificativa violando esses direitos.

Ocorre que, quanto mais o Estado for maior, a interferência na vida dos cidadãos se torna cada vez mais frequente.

Em suma, deve o Estado olhar para o ser humano em todas as suas dimensões, tanto individual ou social. O tratamento deve ser proporcional para que o bem comum, ou seja, o bem de todos, seja também o bem de cada individuo.

Nesse sentido, não pode o Estado agir de maneira que viole a liberdade individual com a desculpa de estar garantido o bem de todo um povo, sendo que é o indivíduo, quando em conjunto com outros, se completam, e dessa somatória o resultado é o bem de todos.

Ora, a sociedade não é um corpo, mas são vários corpos que formam uma sociedade.

Segundo Phillips (apud HAYEK, 2014, p. 26) sem a liberdade individual há redução no progresso:

Ao longo da história, oradores e poetas têm exaltado a liberdade, mas ninguém ainda nos ensinou por que a liberdade é tão importante. A visão da civilização como algo estático ou como algo em evolução deveria determinar nossa atitude diante destas questões. (...) Numa sociedade em evolução, qualquer restrição à liberdade limita o número de experiências possíveis, reduzindo, dessa forma, o ritmo do progresso. Em tal sociedade, a liberdade de ação não é assegurada ao indivíduo porque isso Ihe dá maior satisfação, mas porque, 
se lhe for permitido escolher seu próprio caminho, poderá, de modo geral, servirmos melhor do que se obedecesse às nossas ordens.

A conquista da liberdade passa por toda história em um processo lento, que figura numa luta constante do ser humano, não apenas uma luta política, mas uma necessidade intrínseca de ser plenamente livre.

Em um Estado em que o cidadão é plenamente livre, a postura adotada pelo Estado é o respeito às escolhas dos cidadãos na vivência em sociedade, inclusive a liberdade de autodefesa.

Rebelo (2019, p. 322) traz um ponto interessante ao analisar essa questão à luz da Constituição Federal, em que o direito à vida é um dos alicerces primordiais no ordenamento jurídico brasileiro, e que a defesa individual é o meio principal para defendê-la, e prossegue:

Considerando essa estrutura jurídica, não deveria suscitar maiores discussões o fato de a autodefesa, essencialmente, um direito individual, ou seja, a prerrogativa que é dada ao individuo de manter a sua existência, de fato, inviolável. Uma verdadeira garantia de liberdade para adotar as condutas indispensáveis a fim de continuar vivo.

Vale ressaltar que esse direito ao acesso à defesa não deve ser confundido com a segurança pública, esta cabe exclusivamente ao Estado, enquanto o direito ao acesso à defesa é um direito individual, do qual o que se busca não é a diminuição da violência ou algo do gênero, mas sim a proteção individual, reforçando ainda mais quando a segurança pública é negligenciada.

O Estatuto do Desarmamento, ao propor a restrição do porte de arma de fogo, atinge em cheio as liberdades individuais dos cidadãos, retirandoIhe o direito natural de se proteger.

$\mathrm{Na}$ certeza de que nenhum direito é absoluto, o acesso à defesa, como característica do direito a liberdade, deve ser exercido com responsabilidade, fazendo com que o Estado tenha o dever de regulamentar, assim como ocorre nas relações sociais, o processo de como se dará o uso desse direito.

Além disso, o Estatuto do Desarmamento vai de encontro com o que é contemplado na Constituição Federal:
"Art. $5^{\circ}$ Todos são iguais perante a lei, sem distinção de qualquer natureza, garantindo-se aos brasileiros e aos estrangeiros residentes no País a inviolabilidade do direito à vida, à liberdade, à igualdade, à segurança e à propriedade [...]."

O texto constitucional reafirma o nosso entendimento ao indicar que é inviolável o direito à vida, à liberdade, à igualdade, à segurança e à propriedade.

Sem possibilitar que o cidadão tenha o acesso à defesa, o Estado torna-se violador da própria Constituição, a qual tem o direito de garantir a inviolabilidade.

Como é possível garantir a vida, segurança e propriedade sem a liberdade de protegê-las? Os direitos se completam, é no acesso à defesa que o cidadão é contemplado pela liberdade de protegerIhe a vida, propriedade e a segurança, não apenas de si, mas de toda sua família.

\subsection{Direitos fundamentais}

Afirma Martins que no conceito de Bobbio (1909) "os direitos fundamentais é a concreção histórica do princípio da dignidade humana" (informação verbal) ${ }^{12}$, logo, para a realização dos valores, do desenvolvimento, da liberdade e dos direitos fundamentais é necessário certo desenvolvimento da sociedade.

Já Reale (apud SCHIEFER) acrescenta

que:

Se o homem, em dado momento de sua história, adquire consciência de seu próprio valor como pessoa, é sinal que nele havia a priori a condição de possibilidade da aquisição desse valor, o qual, uma vez adquirido, se apresenta como uma invariante axiológica. É a luz desse entendimento, que corresponde a um "historicismo axiológico", que apresenta a pessoa como valor-fonte do Direito.

No tocante aos direitos fundamentais ou "direitos humanos" a doutrina separa em gerações ou, como é preferível atualmente, em dimensões de direitos, deduz assim os momentos marcantes que se acumulam as conquistas de direitos.

Não se sabe ao certo quando começa uma e termina outra dimensão, mas que são assim

\footnotetext{
${ }_{12}$ Aula realizada por Ricardo Muciato Martins no Curso de Direito da Universidade Paranaense, em Umuarama, abril de 2018.
} 
determinadas para que o entendimento histórico seja mais claro.

$\mathrm{Na}$ primeira dimensão são tratados dos direitos individuais, em que fica marcado de início a mudança de um Estado autoritário para um Estado de direito, conforme explica Bonavides (1997, p. 563):

Os direitos de primeira geração ou direitos de liberdades têm por titular o indivíduo, são oponíveis ao Estado, traduzem-se como faculdades ou atributos da pessoa e ostentam uma subjetividade que é seu traço mais característico; enfim, são direitos de resistência ou de oposição perante o Estado.

A segunda foi marcada pelo direito de igualdade, essa igualdade refere-se à questão material, assim os são - direitos econômicos, sociais e culturais, é como Bonavides (1997, p. 564) explica que "são os direitos sociais, culturais e econômicos bem como os direitos coletivos ou de coletividade, introduzidos no constitucionalismo das distintas formas de Estado social, depois que germinaram por obra da ideologia e da reflexão antiliberal do século XX".

A terceira tratou-se dos princípios da solidariedade e da fraternidade, se deu pelo atrito internacional e pela precariedade em relação ao desenvolvimento, sua destinação envolve todo o gênero humano, como em relação ao desenvolvimento, meio ambiente, comunicação, entre outros, não se prende apenas numa perspectiva individual, mas em um coletivo.

A quarta dimensão vem encerrar a fase de institucionalização do Estado social que resulta na globalização dos direitos fundamentais, como afirma Bonavides (1997, p. 571):

São direitos de quarta geração o direito à democracia, o direito à informação e o direito ao pluralismo. Deles depende a concretização da sociedade aberta do futuro, em sua dimensão de máxima universalidade, para qual parece o mundo inclinar-se no plano de todas as relações de convivências.

Alguns autores têm defendido a existência de direitos fundamentais de quinta geração, mas ainda não há uma consolidação a respeito.
Os direitos fundamentais se tornaram a base legal de toda Constituição, que assume firmemente os preceitos dos direitos fundamentais.

A nossa Constituição enaltece esses direitos e estabelece garantias para o efetivo cumprimento dos direitos conquistados nas dimensões já citadas. É o que se vê no título II, que são expressamente determinados os direitos e deveres individuais e coletivos que estão no conhecido artigo $5^{\circ}$.

Em nossa Constituição Federal os direitos fundamentais estão presentes no artigo $5^{\circ}$, assegurando a todo cidadão a inviolabilidade do direito à vida, à liberdade, à igualdade, à segurança e à propriedade.

É o Estado o principal responsável pela garantia dos direitos fundamentais, é ele que tem o dever e o compromisso de fazer cumprir essas garantias, no entanto, ao observar a ação do Estado no cumprimento desses direitos, a eficácia é relativamente baixa, se comparado a uma empresa, poderíamos dizer que sua salvação só seria possível com uma ação de falência.

Em relação à segurança, o Brasil tornouse um dos países mais inseguros do mundo, as taxas de criminalidade são cada dia maiores e assustadoras e as politicas públicas de segurança não alcançam os níveis desejáveis.

É evidente que o Estado tem sido falho no tocante ao cumprimento desses direitos, o que nos leva a entender que o direito à vida, à segurança e à propriedade só é possível com uma alternativa mais eficaz, o porte de arma de fogo tem se mostrado cada vez mais necessário como essa alternativa viável.

O que é de se questionar é que além do Estado ser ineficaz na proteção e garantia dos direitos fundamentais, a própria constituição deixa claro que todos, todos sem exceção, têm direito à liberdade, ora, se todo cidadão tem direito à liberdade e o Estado é falho em protegê-lo, tanto a vida quanto os bens, por que o Estado priva a sua liberdade em ter o porte de arma de fogo?

A segurança pública é tutelada pela nossa constituição no artigo 144, e estabelece:

Art. 144. A segurança pública, dever do Estado, direito e responsabilidade de todos, é exercida para a preservação da ordem pública e da incolumidade das pessoas e do patrimônio... (BRASIL, 1988). 
Não há dúvidas que o Estado tem o dever de dar segurança pública a todo cidadão, ele se compromete com o cumprimento desse dever, sem esse cumprimento não se pode dizer que é verdadeiramente livre, pois sem segurança pública não há garantia de liberdade e sem liberdade não há direitos fundamentais.

O porte de arma de fogo é a garantia alternativa que muitos recorrem para se ter essa segurança, já que o Estado é incapaz de garanti-la.

\section{CONSIDERAÇÕES FINAIS}

O estudo, em fase de conclusão, vem demonstrando que a vedação ao acesso, em que se transformou ilegitimamente o conjunto de restrições impostos pelo aparato de fiscalização, fere o direito à liberdade do indivíduo, bem como ao direito fundamental de acesso à defesa própria e dos seus, a ser facultada pelo Estado por meio de atos de fiscalização.

Os problemas demostrados levam-nos a entender que é preciso uma legislação capaz de proteger o direito individual do cidadão, e ao mesmo tempo estabelecer medidas de fiscalização, onde aqueles que desejam não possuir uma arma de fogo sintam-se protegidos no meio social pelo Estado.

Além de garantir esse direito, o Estado deve buscar meios necessários para o aperfeiçoamento da segurança pública, pois o acesso à defesa de si não exclui a responsabilidade do Estado da proteção social, tampouco esse direito deve ser usado como politica de segurança nacional.

As legislações vigentes no país, que têm fundamento central na restrição ao acesso à defesa, devem ser colocadas em cheque, levando os legisladores a buscar fundamentos e dados científicos que sustentem tais medidas de restrições.

Medidas essas que foram aprovadas com base na propaganda de uma diminuição dos índices de criminalidade, acreditando os legisladores que numa sociedade mais armada a criminalidade tende a crescer, enquanto que numa sociedade que possua um controle mais rígido e restrições mais firmes os índices de criminalidade seriam menores.

Essa afirmação, usada como embasamento para a aprovação do Estatuto do Desarmamento não tem sustentabilidade nos fatos reais, inclusive tendo a ONU certificando que tal afirmativa não pode ser sustentada, "pois não é possível estabelecer uma relação direta entre a quantidade de armas legais com homicídios" (REBELO, 2019 p 83), e que nos homicídios "frequentemente quem puxa o gatilho são criminosos [com armas ilegais]" (Global Study on Homicide 2011) ${ }^{13}$.

O direito à autodefesa é direito fundamental, é direito natural que deve ser preservado e protegido pelo Estado.

\section{REFERÊNCIAS}

ATLAS da Violência. IPEA - Instituto de Pesquisa Econômica Aplicada. Brasília. Disponível em: https://www.ipea.gov.br/ atlasviolencia/. Acesso em: 23 ago. 2020.

BOBBIO, Norberto; MATTEUCCI, Nicola; PASQUINO, Gianfranco. Dicionário de política. 11. Ed. Brasília: Editora Universidade de Brasília. 1998. $1330 \mathrm{p}$.

\section{BONAVIDES, Paulo. Curso de direito} constitucional. 15. ed. São Paulo: Saraiva, 2004. $806 \mathrm{p}$.

\section{BRASIL. [Constituição (1988)]. Constituição da}

Republica Federativa do Brasil: promulgada em 5 de outubro de 1988. Brasília: Senado Federal. Coordenação de Edições Técnicas. 2016. 496 p.

BRASIL. Código Criminal do Império, de 16 de dezembro de 1830. Manda executar o Código Criminal. 1830. Disponível em: http://www.planalto. gov.br/ccivil_03/leis/lim/lim-16-12-1830.htm. Acesso em: 22 set. 2020.

\section{BRASIL. Decreto $n^{\circ} 847$, de 11 de outubro de} 1890. Promulga o Código Penal. Brasília: Senado Federal. 1890. Disponível em: http://www.planalto. gov.br/ccivil_03/decreto/1851-1899/d847.htm. Acesso em: 10 set. 2020.

\section{BRASIL. Decreto n' 3.665 , de 20 de novembro} de 2000. Dá nova redação ao Regulamento para a Fiscalização de Produtos Controlados (R-105). Brasília: Planalto. 2000. Disponível em: http:// www.planalto.gov.br/ccivil_03/decreto/d3665.htm. Acesso em: 03 Ago. 2020.

\section{BRASIL. Decreto $n^{\circ} \mathbf{9 . 8 4 5}$, de 25 de junho de}

\footnotetext{
${ }_{13}$ Disponível em: https://www.unodc.org/unodc/en/data-and-analysis/ statistics/crime/global-study-on-homicide-2011.html. Acesso em: 10 set. 2020 .
} 
2019. Regulamenta a Lei $n^{\circ} 10.826$, de 22 de dezembro de 2003, para dispor sobre a aquisição, o cadastro, o registro e a posse de armas de fogo e de munição. Brasília: Planalto. 2019. Disponível em: http://www.planalto.gov.br/ccivil_03/_ato20192022/2019/decreto/D9845.htm. Acesso em: 27 jul. 2020.

BRASIL. Decreto $n^{\circ} \mathbf{1 0 . 0 3 0}$, de $\mathbf{3 0}$ de setembro de 2019. Aprova o Regulamento de Produtos Controlados. Brasília: Senado Federal. 2019. Disponível em: http://www.planalto.gov.br/ ccivil_03/ato2019-2022/2019/decreto/D10030. htm. Acesso em: 22 set.2020.

\section{BRASIL. Decreto ${ }^{\circ}$ 92.795, de 18 de junho} de 1986. Dispõe sobre o registro e autorização federal para porte de arma de fogo, de uso permitido, no território nacional. Brasília: Planalto. 1986. Disponível em: http://www.planalto.gov.br/ ccivil_03/decreto/1980-1989/1985-1987/D92795. htm. Acesso em: 10 set. 2020.

\section{BRASIL. Lei 9.437, de 20 de fevereiro de 1997.} Institui o Sistema Nacional de Armas - SINARM, estabelece condições para o registro e para o porte de arma de fogo, define crimes e dá outras providências. Brasília: Senado Federal. 1997.

Disponível em: http://www.planalto.gov.br/ccivil_03/ leis/l9437.htm. Acesso em: 23 ago. 2020.

\section{BRASIL. Lei $\mathbf{n}^{\circ}$. 10.826, de 22 de dezembro}

de 2003. Dispõe sobre registro, posse e comercialização de armas de fogo e munição, sobre o Sistema Nacional de Armas - Sinarm, define crimes e dá outras providências. Brasília: Senado Federal, 2003. Disponível em: http://www. planalto.gov.br/ccivil_03/leis/2003//10.826.htm. Acesso em: 20 jul. 2020.

BRASIL. Relatório da Presidência: Senado Federal e Congresso Nacional. Brasília: Senado Federal. 2005. 1063 p.

CAVALCANTI, Roberto. Democracia. Portal Correio. ano 2017. Opinião. Disponível em: https://correiodaparaiba.com.br/colunas/ democracia/. Acesso em: 23 ago. 2020.

FERREIRA, Aurélio Buarque de Holanda. Mini Aurélio: o dicionário da língua portuguesa. 8. Ed. Curitiba, PR: Positivo, 2010. 960 p.

HAYEK, Friedrich. A. Os fundamentos da liberdade. Goiânia, GO: Visão. 1983.

JESUS, Damásio. E. de. Porte de arma de fogo: seu controle pelas Nações Unidas e Brasil.

Revista Jus Navigandi. 23 dez. 1998. Disponível em: https://jus.com.br/artigos/1035. Acesso em: 10 out. 2020.

\section{LENZA, Pedro. Direito constitucional} esquematizado. 20. ed. São Paulo: Saraiva, 2016. 1866 p.

RODRIGUES NETO, Erasmo. Leis de Armas de Fogo: conheça o histórico e o que permanece vigente. Portal do Tiro. Curitiba, 20 jan. 2020. Disponível em: https://www.portaldotiro.com/ artigos-tecnicos/legislacao-de-armas/534-leisde-armas-de-fogo-conheca-o-historico-e-o-quepermanece-vigente. Acesso em: 20 out. 2020.

QUINTELA, Flavio; BARBOSA, Bene. Mentiram para mim sobre o desarmamento. 1. ed. Campinas, SP: Vide Editorial, 2015.

REBELO, Fabricio. Articulando em segurança: contrapontos ao desarmamento civil. 3. Ed. São José dos Campos, SP: Burke Editorial, 2019. 420 p.

\section{SCHIEFER, Uyára. Sobre os direitos} fundamentais da pessoa humana. Revista Persona. Disponível em: https://www. revistapersona.com.ar/Persona28/28Schiefer.htm. Acesso em: 18 Ago. 2020.

TEIXEIRA, João Luís Vieira. Armas de fogo: elas não são as culpadas. 2. ed. São Paulo: LTr, 2018.

\section{LIBERTAD INDIVIDUAL, DERECHO FUNDAMENTAL DE ACCESO A LA DEFENSA - EVOLUCIÓN DE LA LEGISLACIÓN NACIONAL SOBRE ARMAS}

Resumen: El propósito de este artículo, basado en la investigación bibliográfica y las disposiciones legales, es analizar las posibilidades de posesión y porte de armas de fuego, como derecho fundamental a la defensa propia y a la libertad individual, aplicando una visión crítica sobre los actos de restricciones en relación con la autodefensa (de uno mismo) y ajena (de los demás) con el objetivo de dar mayor efectividad a los derechos fundamentales individuales vinculadas a su propia existencia. La Constitución Federal garantiza el derecho a la libertad de todos los ciudadanos, y es a través de ella que habrá plena posibilidad de proteger la vida, ya que la efectividad del Estado en la protección de esos derechos 
es relativamente baja. La investigación demuestra que el mejor camino es la liberación juiciosa del acceso a los medios de protección individual, incluso en relación con las armas de fuego. Por sensatez, no se puede entender la prohibición encubierta que existe actualmente en el aparato federal de (des) aprobación de solicitudes de registro de armas de fuego. El estudio demuestra que la prohibición de acceso, en la que se ha transformado ilegítimamente el conjunto de restricciones impuestas por el aparato de inspección, vulnera el derecho de la persona a la libertad, así como el derecho fundamental a la legítima defensa y de los suyos.

Palabras clave: Libertad individual; Derecho fundamental; Acceso a la defensa; Armas de fuego. 